\title{
Synthesis and characterization of hyperbranched aromatic poly(ether ketone)s functionalized with carboxylic acid terminal groups
}

\author{
Ying Shi ${ }^{1}$, Yuta Nabae ${ }^{1}$, Teruaki Hayakawa ${ }^{1}$, Hirokazu Kobayashi ${ }^{2}$, Mizuho Yabushita ${ }^{2,3}$, \\ Atsushi Fukuoka ${ }^{2}$ and Masa-aki Kakimoto ${ }^{1}$
}

A new type of hyperbranched aromatic poly(ether ketone) terminated with carboxylic acid groups (P2) was synthesized via a one-step polycondensation of a symmetric $A B_{2}$ monomer, 4,4'-(m-phenylenedioxy)-bis(benzenecarboxylic acid), using phosphorous pentoxide-methanesulfonic acid (PPMA) as a condensing agent and solvent. Subsequently, the terminal carboxylic acid functional group of $\mathbf{P} 2$ was converted to an ethyl ester functional group by treatment with thionyl chloride followed by ethanol in the presence of triethylamine. The weight-average molecular weight $\left(M_{\mathrm{w}}\right)$ of the ethyl ester-terminated hyperbranched poly(ether ketone) (P3) was measured by gel permeation chromatography. By changing the reaction time and the amount of PPMA, $M_{\mathrm{w}}$ can be controlled in the range of $4.2 \times 10^{4}$ to $1.6 \times 10^{5}$. P2 was soluble in polar solvents, and P3 was soluble in less-polar solvents. The thermal stabilities of the poly(ether ketone)s were investigated using thermogravimetric analysis, which indicated that the decompositions of P2 and P3 start at around 150 and $200{ }^{\circ} \mathrm{C}$, respectively. The inherent viscosities of P2 were in the range of $0.101-0.171$, while those of $\mathrm{P3}$ ranged from 0.067 to 0.112 . The ion exchange capacities calculated by

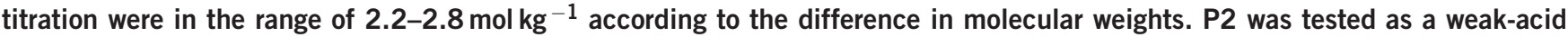
catalyst and exhibited a certain catalytic activity for the hydrolysis of cellulose to glucose.

Polymer Journal (2014) 46, 722-727; doi:10.1038/pj.2014.62; published online 16 July 2014

\section{INTRODUCTION}

Since Kim and coworkers defined hyperbranched polymers (HBPs) in the $1980 \mathrm{~s},{ }^{1-3}$ these materials have been a topic of considerable interest in the fields of polymer science and engineering. Compared to linear polymers, HBPs possess properties similar to those of dendrimers, such as weak molecular entanglement, low viscosities, high solubilities and large numbers of functional groups, because they have numerous branching points and terminal groups. ${ }^{4-9}$ Dendrimers with precise molecular weights and exact numbers of repeating units must be constructed via multistep processes that require isolation and purification in each step, ${ }^{10-13}$ which necessitates laborious syntheses and are difficult to scale up. In contrast, HBPs can be prepared via a one-step synthesis, which is suitable for large-scale production, although the resulting HBPs consist of a mixture of different molecular weights. ${ }^{14}$ The polycondensation of $\mathrm{AB}_{x}$ monomers is the most widely studied method for preparing hyperbranched polymers. Various hyperbranched polymers, such as polyphenylene, ${ }^{3}$ polyesters, ${ }^{15-18}$ polycarbonates, ${ }^{19,20}$ polyamides, ${ }^{21-23}$ polyimides, ${ }^{24-26}$ poly(ether sulfone) $s^{27,28}$ and poly(ether ketone)s, ${ }^{29-33}$ have been synthesized to date.
In terms of the potential applications of HBPs, our research group has been particularly interested in hyperbranched aromatic polymers with acidic functional groups. Such polymers will exhibit acidic functionality in various environments because of their high thermal and chemical stabilities. For instance, we have successfully synthesized a hyperbranched aromatic poly(ether sulfone) with sulfonic acid terminal groups and proposed it as a promising proton-conductive membrane for fuel cells. ${ }^{27,28}$ In addition to such strongly acidic functional groups, weakly acidic groups, such as carboxylic acid, are also of interest as the terminal functional groups of HBPs. Several studies have reported that weakly acidic groups on carbons catalyze the hydrolysis of polysaccharides in water at $150-170{ }^{\circ} \mathrm{C} .{ }^{34-36}$ If many carboxylic groups could be introduced on the terminals of a thermally stable HBP, for example, hyperbranched poly(ether ketone), the resulting material would be a quite active and stable catalyst for biomass conversion.

Shu and Leu ${ }^{30}$ previously reported the synthesis of a hyperbranched poly(ether ketone) with carboxylic acid terminal groups through the polycondensation of an $\mathrm{AB}_{2}$-type monomer, 5-phenoxyisophthalic acid. Because the two carboxyl groups were

${ }^{1}$ Department of Organic and Polymeric Materials, Graduate School of Science and Engineering, Tokyo Institute of Technology, Tokyo, Japan; ${ }^{2}$ Catalysis Research Center, Hokkaido University, Hokkaido, Japan and ${ }^{3}$ Division of Chemical Sciences and Engineering, Graduate School of Chemical Sciences and Engineering, Hokkaido University, Hokkaido, Japan

Correspondence: Professor M-a Kakimoto, Department of Organic and Polymeric Materials, Graduate School of Science and Engineering, Tokyo Institute of Technology, 2-12-1 S8-26 Ookayama, Meguro-ku, Tokyo 152-8552, Japan.

E-mail: mkakimot@o.cc.titech.ac.jp

Received 23 March 2014; revised 1 May 2014; accepted 14 May 2014; published online 16 July 2014 


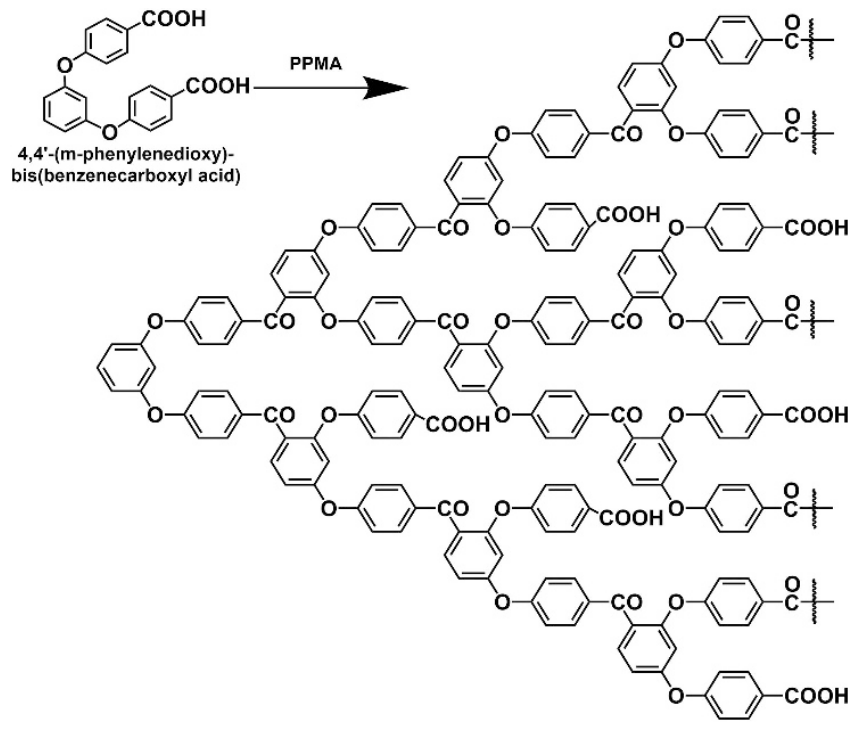

Figure 1 Structures of the hyperbranched poly(ether ketone)s.

present on the same benzene ring, the activity of the B terminal was limited by steric hindrance and resulted in a relatively low molecular weight $\left(M_{w}\right)$ of $<15000$.

In this context, we propose $4,4^{\prime}$-( $m$-phenylenedioxy)-bis(benzenecarboxylic acid) as a symmetric $\mathrm{AB}_{2}$ monomer for the synthesis of hyperbranched aromatic poly(ether ketone)s via a Friedel-Crafts reaction, as illustrated in Figure 1. Although this monomer is a known compound, ${ }^{37,38}$ it has not been utilized as an $\mathrm{AB}_{2}$ monomer. The $\mathrm{B}$ terminals are expected to exhibit high reactivity due to the high flexibility derived from the ether bonds and less steric hindrance; therefore, higher molecular weights can be expected. Moreover, the B terminals can be utilized as a weak-acid terminal without any endcapping reaction. This study describes the details of the preparation of new hyperbranched poly(ether ketone)s with various molecular weights and their physicochemical properties. Moreover, to investigate the functionality of the terminal groups, a model catalytic reaction, the hydrolysis of cellulose to glucose, which is an important reaction in biomass conversion, was investigated using the prepared polymer.

\section{EXPERIMENTAL PROCEDURE}

\section{Measurements}

Nuclear magnetic resonance (NMR) $(1 \mathrm{H}, 400 \mathrm{MHz})$ spectra were recorded for samples dissolved in chloroform- $d$ or dimethyl sulfoxide- $d_{6}$ using a JEOL JNM-ECS 400 NMR spectrometer (JEOL Ltd., Tokyo, Japan). FTIR spectra were recorded with a Jasco 4100 spectrometer (JASCO Inc., Easton, MD, USA) using the $\mathrm{KBr}$ pellet method. Gel permeation chromatography (GPC) was performed using a Viscotek GPC-1000 system (Malvern Instruments Ltd., Malvern, UK) equipped with a TDA 302 triple detector and a TSK-GEL $\alpha-\mathrm{M}$ column. Dimethylformamide (DMF) containing $0.05 \mathrm{M} \mathrm{LiBr}$ was used as the eluent. The weight-average molecular weight $M_{w}$ was calculated from lightscattering data. Thermogravimetric analysis was performed under nitrogen using an SII TGA 7300 system (SII NanoTechnology Inc., Tokyo, Japan) at a heating rate of $10^{\circ} \mathrm{C} \mathrm{min}^{-1}$. Differential scanning calorimetry was performed under nitrogen using an SII DSC 7020 system at a heating rate of $10^{\circ} \mathrm{C} \mathrm{min}^{-1}$. The inherent viscosity was measured with $0.5 \mathrm{~g} \mathrm{dl}^{-1}$ of polymer solution in dimethylacetamide using an Ostwald viscometer in a thermostatic bath at $30^{\circ} \mathrm{C}$. The solubility of the polymer was qualitatively examined by adding $6 \mathrm{mg}$ of polymer to $2 \mathrm{ml}$ of solvents. The ion exchange capacity was determined as follows. Thirty milligrams of polymer sample was stirred in a $0.1 \mathrm{M} \mathrm{NaOH}$ solution $(3 \mathrm{ml})$ overnight and then diluted to $10 \mathrm{ml}$ with deionized water. The obtained solution was titrated with a $0.05 \mathrm{M} \mathrm{HCl}$ standard solution.

\section{Materials}

Resorcinol, 4-nitrobenzonitrile, methanesulfonic acid, thionyl chloride and triethylamine were purchased from TCI (Tokyo Chemical Industry Co., Ltd., Tokyo, Japan). Microcrystalline cellulose was purchased from Merck Millipore (Tokyo, Japan) (Avicel, 102331). Potassium carbonate, potassium hydroxide, phosphorus pentoxide and distilled water were purchased from Wako Pure Chemical Industries, Ltd., Osaka, Japan. Phosphorous pentoxide-methanesulfonic acid (PPMA, $7.7 \mathrm{wt} \%$ phosphorus pentoxide solution in methanesulfonic acid) was used immediately after preparation. All of the chemicals were used as received unless stated otherwise.

\section{Synthesis of $4,4^{\prime}$-(m-phenylenedioxy)-bis benzenenitrile}

In a $100-\mathrm{ml}$ flask, resorcinol $(1.11 \mathrm{~g}, 10.0 \mathrm{mmol})$ and 4-nitrobenzonitrile $(3.02 \mathrm{~g}, 20.0 \mathrm{mmol})$ were dissolved in $60 \mathrm{ml}$ of dimethylformamide. Then, potassium carbonate $(6.98 \mathrm{~g}, 50 \mathrm{mmol})$ was added to the flask. The mixture was stirred at $120^{\circ} \mathrm{C}$ for $48 \mathrm{~h}$ and then poured into $1000 \mathrm{ml}$ of water. The product was collected by filtration, washed three times with water and then dried under vacuum. Yield: $90 \% .{ }^{1} \mathrm{H}$ NMR $\left(\mathrm{CDCl}_{3}, \delta\right.$, p.p.m.): 7.64 (d, $\left.4 \mathrm{H}\right)$, $7.43(\mathrm{t}, 1 \mathrm{H}), 7.06(\mathrm{~d}, 4 \mathrm{H}), 6.93-6.90(\mathrm{dd}, 2 \mathrm{H}), 6.79(\mathrm{~s}, 1 \mathrm{H})$.

\section{Synthesis of 4,4'-(m-phenylenedioxy)-bis(benzenecarboxylic acid)}

(1)

In a $200-\mathrm{ml}$ flask equipped with a reflux condenser, $4,4^{\prime}$-( $m$-phenylenedioxy)bis benzenenitrile $(1.56 \mathrm{~g}, 5 \mathrm{mmol})$ and potassium hydroxide $(2.81 \mathrm{~g}, 50 \mathrm{mmol})$ were dissolved in $120 \mathrm{ml}$ of a water/ethylene glycol (1:1 volume) mixed solvent. The reaction mixture was refluxed at $136^{\circ} \mathrm{C}$ for $4 \mathrm{~h}$ and then poured into $300 \mathrm{ml}$ of water. The $\mathrm{pH}$ value of the solution was adjusted to 1 using a $1 \mathrm{M}$ $\mathrm{HCl}$ aqueous solution. The crude product was collected by filtration and washed with diluted hydrochloric acid and water. After recrystallization from aqueous acetic acid, a pink powdery product was obtained and dried under vacuum. Yield: $96 \%$. ${ }^{1} \mathrm{H}$ NMR (dimethyl sulfoxide- $d_{6}, \delta$, p.p.m.): 12.89 (s, 2H), $7.96(\mathrm{~d}, 4 \mathrm{H}), 7.51(\mathrm{t}, 1 \mathrm{H}), 7.11(\mathrm{~d}, 4 \mathrm{H}), 6.98-6.95(\mathrm{dd}, 2 \mathrm{H}), 6.89$ (s, 1H, e). IR $\left(\mathrm{KBr}, \mathrm{cm}^{-1}\right): 1670(\mathrm{C}=\mathrm{O}$, stretching $), 2500-3000(\mathrm{O}-\mathrm{H}$, vibration, broadband).

Synthesis of hyperbranched poly(ether ketone) with carboxylic acid terminal group (P2)

In a $5-\mathrm{ml}$ flask, $0.3 \mathrm{~g}$ of monomer 1 was mixed with $2 \mathrm{ml}$ of PPMA. ${ }^{39,40}$ The reaction mixture was stirred at $110^{\circ} \mathrm{C}$ for $2 \mathrm{~h}$, poured into water, washed with a large amount of water and then methanol, and finally dried at $80^{\circ} \mathrm{C}$ under vacuum. IR $\left(\mathrm{KBr}, \mathrm{cm}^{-1}\right): 1668(\mathrm{C}=\mathrm{O}$, stretching $), 2500-3000(\mathrm{O}-\mathrm{H}$, vibration, broadband)

\section{Synthesis of hyperbranched poly(ether ketone) with ethyl ester} terminal group $(\mathbf{P} 3)$

To a 5 -ml flask equipped with a reflux condenser was added $0.3 \mathrm{~g}$ of polymer, and then $1.5 \mathrm{ml}$ of thionyl chloride was added drop-wise while stirring. The mixture was gently heated at $100{ }^{\circ} \mathrm{C}$ for $1 \mathrm{~h}(1 \mathrm{ml}$ of thionyl chloride was added after $20 \mathrm{~min}$ ) and then distilled at $70^{\circ} \mathrm{C}$ under atmospheric pressure to remove excess thionyl chloride. Then, the bath temperature was slowly increased to $130{ }^{\circ} \mathrm{C}$ under vacuum until the product, carbonyl chloride-terminated polymer, was fully dried. Ethanol $(3 \mathrm{ml})$ and triethylamine $(0.5 \mathrm{ml}, 3.4 \mathrm{mmol})$ were added to the same flask. The mixture was refluxed at $80^{\circ} \mathrm{C}$ for $4 \mathrm{~h}$ and distilled at $95{ }^{\circ} \mathrm{C}$ under reduced pressure. The obtained product was washed with water and methanol and then dried under vacuum. IR $\left(\mathrm{KBr}, \mathrm{cm}^{-1}\right): 1716(\mathrm{C}=\mathrm{O}$, stretching), 2497, 2604, 2942, $2978\left(\mathrm{CH}_{2}, \mathrm{CH}_{3}\right.$, stretching), 3421 (overtone of $\mathrm{C}=\mathrm{O}$ stretching vibration)

\section{Hydrolysis of cellulose}

As a pretreatment, microcrystalline cellulose $(9.72 \mathrm{~g})$ and P2 $(1.49 \mathrm{~g}$, acid: $3.73 \mathrm{mmol})$ were milled together with alumina balls $(1.5 \mathrm{~cm}, 2 \mathrm{~kg})$ in a ceramic pot (3.6l) at 60 r.p.m. for $48 \mathrm{~h}$. The hydrolysis of cellulose was conducted in a Hastelloy C22 high-pressure reactor (MMJ-100, OM Labtech Enterprises, Mumbai, India, $100 \mathrm{ml})$. The milled sample $(374 \mathrm{mg}$; containing $324 \mathrm{mg}$ of cellulose and $50 \mathrm{mg}$ of catalyst (acid: $0.125 \mathrm{mmol}$ )) and $40 \mathrm{ml}$ of distilled water 
were added to the reactor. The temperature was increased to $230{ }^{\circ} \mathrm{C}$ in $\sim 17 \mathrm{~min}$ and then rapidly cooled to $50^{\circ} \mathrm{C}$ by flowing air. After the reaction, the solid and liquid phases were separated by centrifugation and decantation. The reaction products in the liquid phase were analyzed by high-performance liquid chromatography (Shimadzu LC10-ATVP (Shimadzu Corporation, Kyoto, Japan) with refractive and ultraviolet $(210 \mathrm{~nm})$ detectors) with a Shodex SUGAR SH-1011 column $(\varnothing 8 \times 300 \mathrm{~mm}$, mobile phase: water at $0.5 \mathrm{ml}$ $\min ^{-1}, 50^{\circ} \mathrm{C}$ ) and a Phenomenex Rezex RPM-Monosaccharide $\mathrm{Pb}++$ column $\left(\varnothing 7.8 \times 300 \mathrm{~mm}\right.$, mobile phase: water at $\left.0.6 \mathrm{ml} \mathrm{min}^{-1}, 70^{\circ} \mathrm{C}\right)$. The conversion of cellulose was determined from the weight difference in the solid fraction before and after the reaction.

\section{RESULTS AND DISCUSSION}

\section{Synthesis of hyperbranched poly(ether ketone)}

The hyperbranched aromatic poly(ether ketone) was synthesized as shown in Scheme 1. The $\mathrm{AB}_{2}$ monomer, $4,4^{\prime}$-( $m$-phenylenedioxy)bis(benzenecarboxylic acid), was prepared via a simple route starting from resorcinol and 4-nitrobenzonitrile with a yield of $>86 \%$. The structure of 1 was confirmed by ${ }^{1} \mathrm{H}$ NMR (Figure 2a). The polycondensation of the monomer was conducted in PPMA at $110^{\circ} \mathrm{C}$, which afforded the hyperbranched polymer (P2). Figure $2 \mathrm{~b}$ shows the ${ }^{1} \mathrm{H}$ NMR spectrum of $\mathrm{P} 2$. After polymerization, the peak of carboxylic acid (f, 12.89 p.p.m.) decreased and a new peak (g, 7.28 p.p.m.) appeared, suggesting a successful polycondensation.

Because the GPC for P2 was difficult due to the presence of numerous carboxylic acid groups, the terminal functional group was converted into ethyl ester (P3) and analyzed by GPC (Table 1). Figure 3 shows the ${ }^{1} \mathrm{H}$ NMR spectra of $\mathrm{P} 2$ and $\mathrm{P} 3$ of entry 2.<smiles>Oc1cccc(O)c1</smiles><smiles>O=C(N=Cc1ccc([N+](=O)[O-])cc1)OCc1ccccc1</smiles><smiles>N#Cc1ccc(Oc2cccc(Oc3ccc(C#N)cc3)c2)cc1</smiles>

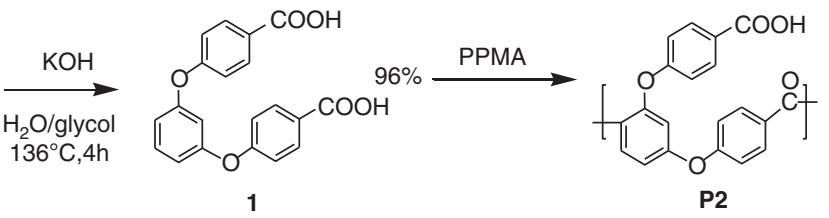

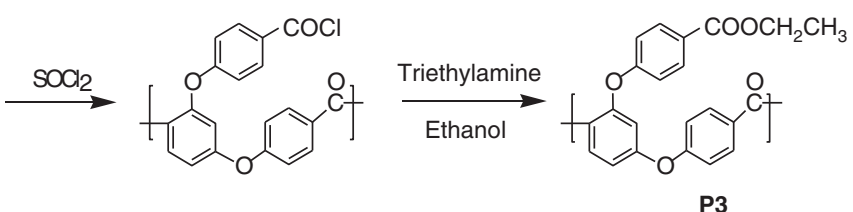

Scheme 1 Synthesis and structures of hyperbranched poly(ether ketone)s with carboxylic acid and ethyl ester as the terminal groups.
Compared to P2, the peak of carboxylic acid (12.89 p.p.m.) disappeared and the peaks of ethyl ester (4.33 and 1.35 p.p.m., with a ratio of 2:3) appeared, which confirmed a successful terminal conversion. The GPC result suggests that the molecular weight of the hyperbranched aromatic poly(ether ketone) can be controlled in the range of $42000-159000$ by changing the polymerization conditions. Note that clearly higher molecular weights have been achieved here in comparison to previously reported work: $M_{\mathrm{w}}<15000$ from 5-phenoxyisophthalic acid. ${ }^{30}$ This high molecular weight is most likely due to the higher reactivity of the B terminal of monomer $\mathbf{1}$.

\section{Physicochemical properties}

The inherent viscosities of P2 and P3 were measured using an Ostwald viscometer, and the results are shown in Table 1. The P2 polymers show inherent viscosities in the range of $0.101-0.171 \mathrm{dl} \mathrm{g}^{-1}$ in dimethylacetamide, and the corresponding ethyl ester-terminated P3 polymers show inherent viscosities in the range of 0.067 $0.112 \mathrm{dlg}^{-1}$. These low viscosity values are most likely due to the quite low degree of entanglement of the hyperbranched polymers. The difference between the viscosities of $\mathrm{P} 2$ and $\mathrm{P} 3$ resulted from the different polarities of the terminal groups.

Table 2 shows the solubilities of the hyperbranched polymers from entry 1. P2 is soluble in basic aqueous solutions, tetrahydrofuran and some polar aprotic solvents, such as dimethyl sulfoxide (DMSO) and dimethylformamide, and it is partially soluble in acetone and insoluble in dichloromethane, chloroform and toluene, among others. However, $\mathrm{P} 3$ is soluble in dichloromethane, chloroform and acetone and partially soluble in toluene and tetrahydrofuran. Note that the aromatic poly(ether ketone) dissolved in several solvents due to the introduction of the hyperbranched structure, whereas typical linear aromatic poly(ether ketone)s are generally known to be insoluble polymers in most solvents. ${ }^{41}$

The thermal stabilities of P2 and P3 were examined by thermogravimetric analysis under a nitrogen atmosphere (Figures 4 and 5).

Table 1 Synthesis of hyperbranched polyetherketone under different conditions

\begin{tabular}{|c|c|c|c|c|c|c|c|c|}
\hline Entry ${ }^{a}$ & $\begin{array}{c}\text { PPMA } \\
(m /)\end{array}$ & $\begin{array}{c}T \\
\left({ }^{\circ} \mathrm{C}\right)\end{array}$ & $\begin{array}{l}\text { Time } \\
\text { (h) }\end{array}$ & $M_{w}{ }^{\mathrm{b}}$ & Yield & $\eta_{i n h, P 2^{c}}$ & $\eta_{i n h, P 3^{c}}$ & $\begin{array}{c}\text { IEC } \\
\left(\mathrm{mol} \mathrm{kg}^{-1}\right)\end{array}$ \\
\hline 1 & 3 & 110 & 2 & 42000 & 84 & 0.101 & 0.067 & 2.8 \\
\hline 2 & 2 & 110 & 2 & 74000 & 84 & 0.127 & 0.081 & 2.5 \\
\hline 3 & 2 & 110 & 6 & 123000 & 94 & 0.133 & 0.085 & 2.3 \\
\hline 4 & 2 & 110 & 10 & 159000 & 92 & 0.171 & 0.112 & 2.2 \\
\hline
\end{tabular}

Abbreviations: IEC, ion exchange capacity; PPMA, phosphorous pentoxide-methanesulfonic acid.

The amount of monomer 1: $300 \mathrm{mg}$

Determined by GPC eluted with dimethylformamide containing lithium bromide $\left(0.05 \mathrm{moll}^{-1}\right)$. cMeasured at a concentration of $0.5 \mathrm{~g} \mathrm{dl}^{-1}$ in DMAc at $30^{\circ} \mathrm{C}$. a

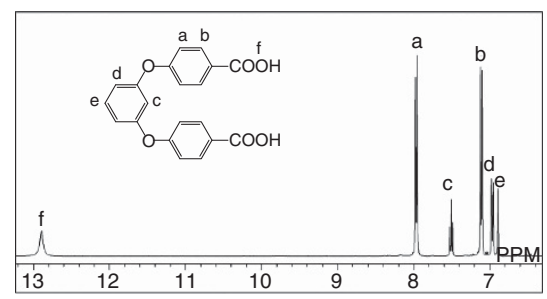

b

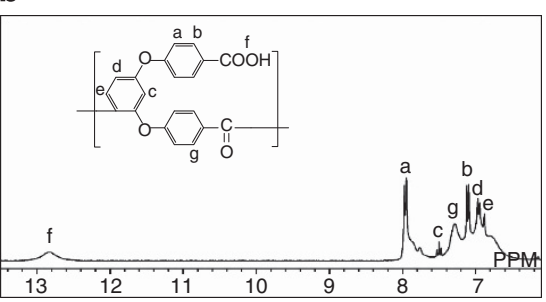

Figure $2{ }^{1} \mathrm{H}$ NMR (DMSO- $d_{6}$ ) spectra of monomer $\mathbf{1}$ (a) and polymer P2 (b). 
a

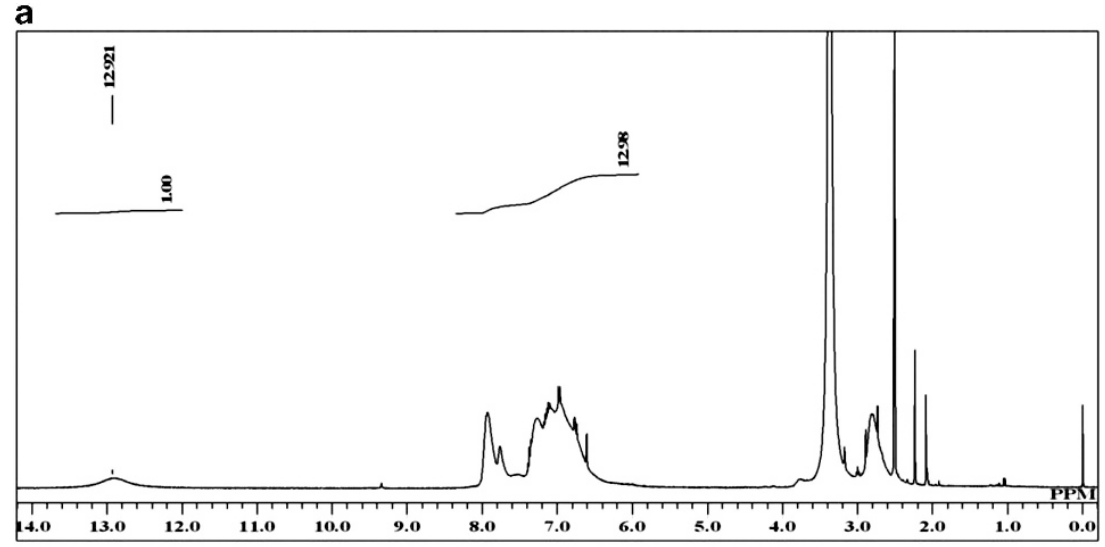

b

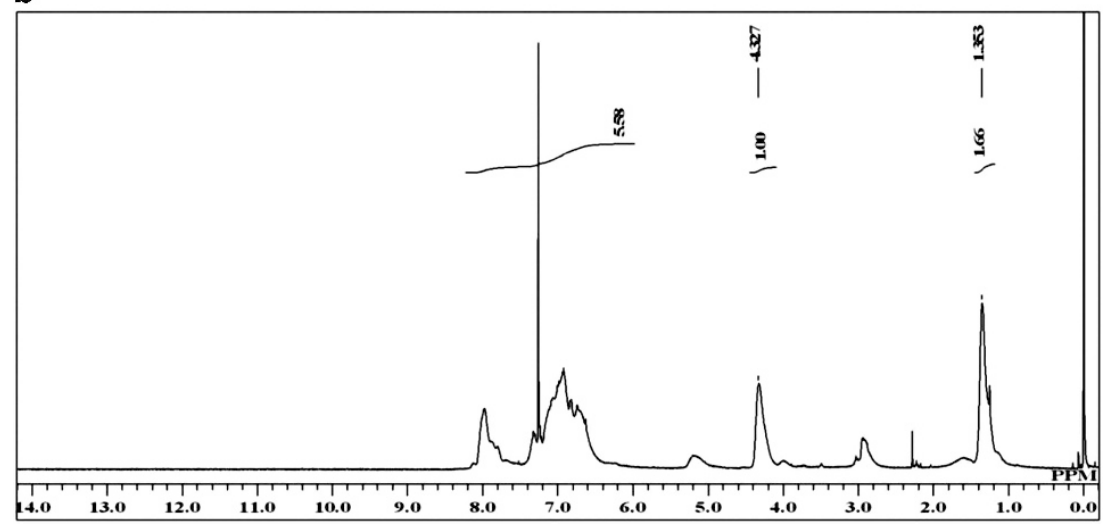

Figure $3{ }^{1} \mathrm{H}$ NMR (DMSO- $d_{6}$ ) spectra of entry 2-P2 (a) and entry 2-P3 (b).

Table 2 Solubility of hyperbranched polymer ${ }^{\mathrm{a}}$

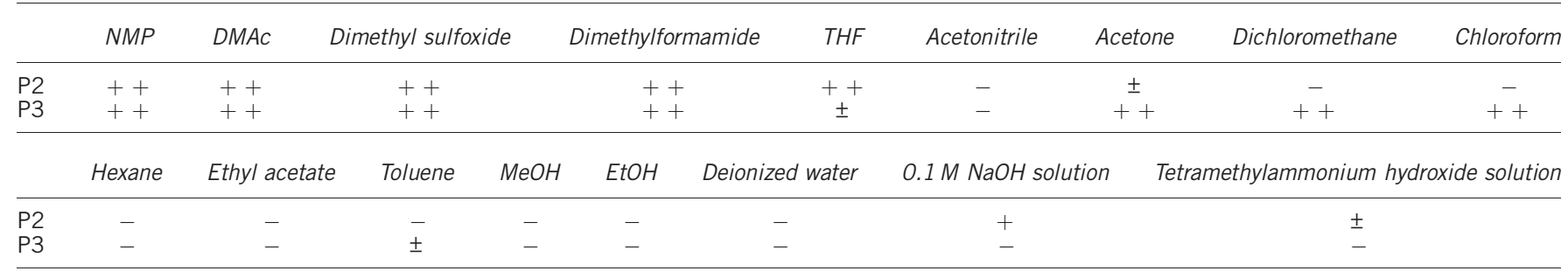

Abbreviations: DMAc, dimethylacetamide; THF, tetrahydrofuran.

$\mathrm{a}_{+}+$, soluble at room temperature; + , soluble on heating; \pm , partially soluble; - , insoluble even on heating.

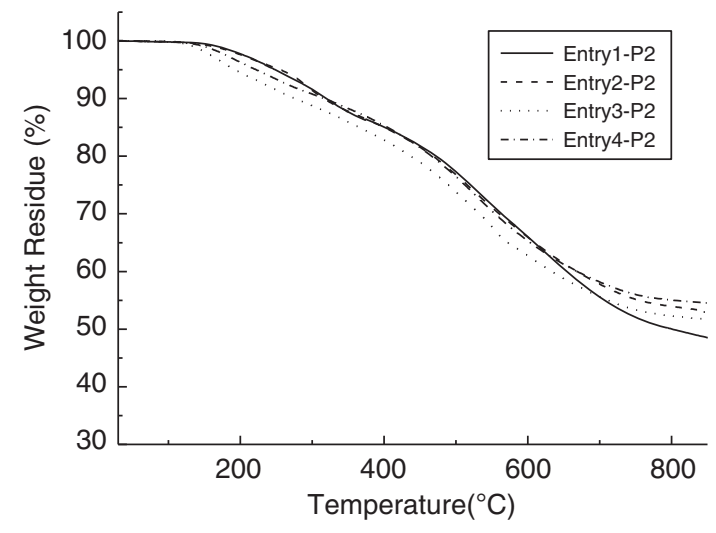

Figure 4 TG curve of entries 1-4 with carboxylic acid terminal groups.

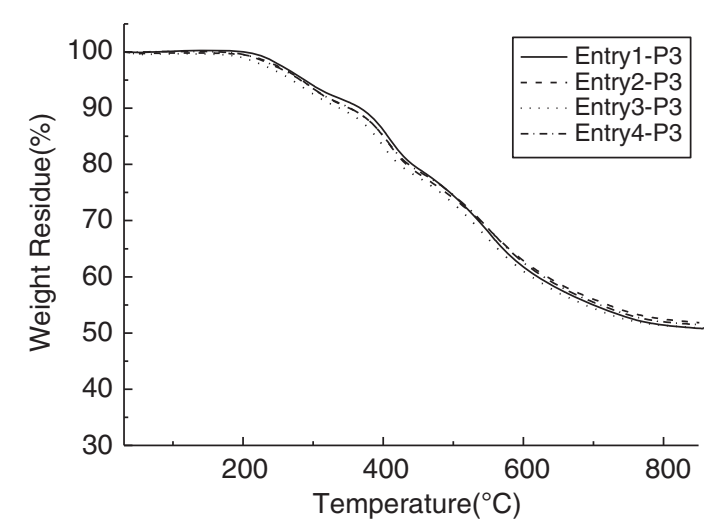

Figure 5 TG curve of entries 1-4 with ethyl ester terminal groups. 


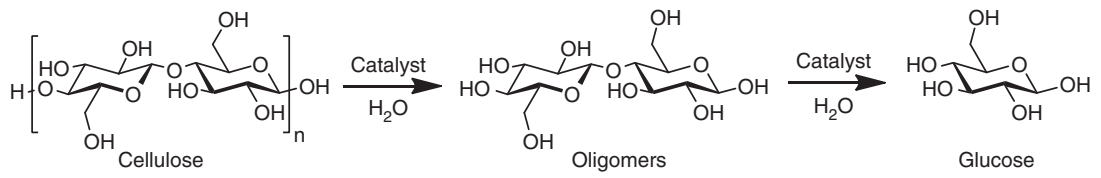

Scheme 2 Hydrolysis of cellulose to glucose.

Table 3 Hydrolysis of cellulose by P2 from entry $2^{\mathrm{a}}$

\begin{tabular}{|c|c|c|c|c|c|c|c|c|c|c|}
\hline \multirow[b]{2}{*}{ Entry } & \multirow[b]{2}{*}{ Catalyst } & \multirow[b]{2}{*}{ Conv. (\%) } & \multicolumn{7}{|c|}{ Yield $(\% \mathrm{C})$} & \multirow[b]{2}{*}{$T_{O N}^{b}$} \\
\hline & & & $G / c$ & Olgc & Man & Frc & Lev & 5-HMF & Others $^{\mathrm{d}}$ & \\
\hline 1 & None & 27 & 4.6 & 15 & 0.6 & 0.5 & 0.2 & 1.8 & 4.8 & - \\
\hline 2 & P2 & $53^{e}$ & 16 & 22 & 0.9 & 1.1 & 0.8 & 3.8 & 8.7 & 1.6 \\
\hline 3 & Benzoic acid & 53 & 19 & 21 & 1.1 & 1.4 & 1.0 & 4.2 & 5.2 & 2.3 \\
\hline
\end{tabular}

Abbreviation: 5-HMF, 5-hydroxymethylfurfural; Frc, fructose; Glc, glucose; Lev, levoglucosan; Man, mannose; Olg, oligomer; TON, turnover number.

${ }^{a}$ Cellulose $324 \mathrm{mg}, \mathrm{P} 250 \mathrm{mg}$ or benzoic acid $14 \mathrm{mg}$, distilled water $40 \mathrm{ml}, 230^{\circ} \mathrm{C}$.

bTurnover number for production of glucose.

'Degree of polymerization= mainly $2-6$.

d(Conversion) - (total yield of shown products).

e For estimation of conversion, we hypothesized that none of P2 dissolved into water.

The weight losses of $\mathrm{P} 2$ and P3 begin at $\sim 150$ and $200^{\circ} \mathrm{C}$, respectively. These initial weight losses are most likely due to the decomposition of the terminal functional groups. The $10 \%$ of weightloss temperatures of all $\mathrm{P} 2$ and $\mathrm{P} 3$ polymers are $>300{ }^{\circ} \mathrm{C}$, suggesting that the poly(ether ketone) backbone possesses high thermal stability. Differential scanning calorimetry measurements for P2 and P3 were performed over the temperature range of -30 to $200^{\circ} \mathrm{C}$. No glass transition temperature was observed, suggesting that the glass transition temperatures of these polymers may be $>200{ }^{\circ} \mathrm{C}$.

\section{Functionality of the carboxylic acid terminals}

The ion exchange capacity of $\mathrm{P} 2$ was evaluated by acid-base titration, and the results are shown in Table 1. Entry 1 shows an ion exchange capacity of $2.8 \mathrm{~mol} \mathrm{~kg}^{-1}$, whereas the theoretical value is $2.9 \mathrm{~mol} \mathrm{~kg}^{-1}$. As the weight-average molecular weight increases, the amount of titrated carboxylic acid decreases. Presumably, some terminal groups are hidden in the polymer matrix or a cross-linking reaction decreased the number of terminals as the molecular weight increased.

The hydrolysis of cellulose was employed as a catalytic reaction (Scheme 2) to investigate the functionality of the terminal groups of P2 from entry 2. Table 3 summarizes the results of the catalytic reaction. P2 clearly shows a higher conversion of cellulose than the blank test. The conversion of cellulose and the yield of glucose reached 53 and 16\%, respectively, after the reaction period. The turnover number was 1.6, which was calculated from the difference between the glucose yields of P2 and blank, whereas a control experiment with benzoic acid showed a turnover number of 2.3 . These experimental results suggest that the carboxylic acid groups on the terminals of the hyperbranched poly(ether ketone)s functioned as a weak-acid catalyst. The present results suggest that P2 has potential applications as a heterogeneous catalyst, although the solubility and catalytic activity of the polymer requires optimization. Further studies will be performed to investigate the stability of the current material under severe reaction conditions and to optimize the polymer structure to develop highly active and stable catalyst materials.

\section{CONCLUSIONS}

A new type of hyperbranched aromatic poly(ether ketone) that possesses carboxylic acid terminal groups has been successfully synthesized via a one-step polycondensation of a symmetric $A_{2}$ monomer 1, using PPMA as a condensing agent and solvent. The weight-average molecular weight can be controlled in the range of $4.2 \times 10^{4}$ to $1.6 \times 10^{5}$ by changing the polymerization conditions. The hyperbranched polymer exhibited good solubility in organic solvents, and the solubility could be changed by converting the terminal groups. Thermogravimetric analysis suggested that these polymers possessed good thermal stability. The catalytic activity of the carboxylic acid terminal groups was demonstrated by the hydrolysis of cellulose. Considering the development possibilities for carboxylic acid functionality, the present hyperbranched poly(ether ketone)s have potential for a wide range of applications.

\section{ACKNOWLEDGEMENTS}

M Kakimoto was supported by a Visiting Professorship for Senior International Scientists from the Chinese Academy of Sciences.

1 Kim, Y. H. Hyperbranched polyarylene. US Patent 4857630 (1987).

2 Kim, Y. H. \& Webster, O. W. Water soluble hyperbranched polyphenylene: "a unimolecular micelle?". J. Am. Chem. Soc. 112, 4592-4593 (1990).

3 Kim, Y. H. \& Webster, O. W. Hyperbranched polyphenylenes. Macromolecules 25, 5561-5572 (1992)

4 Tomalia, D. A., Naylor, A. M. \& Goddard, W. A. Starburst dendrimers: molecular-level control of size, shape, surface chemistry, topology, and flexibility from atoms to macroscopic matter. Angew. Chem. Int. Ed. Engl. 29, 138-175 (1990).

5 Tomalia, D. A. \& Durst, H. D. Genealogically directed synthesis - starburst cascade dendrimers and hyperbranched structures. Top. Curr. Chem. 165, 193-313 (1993).

6 Newkome, G. R., Moorefield, C. N., Baker, G. R., Johnson, A. L. \& Behera, R. K. Alkane cascade polymers possessing micellar topology: micellanoic acid derivatives. Angew. Chem. Int. Ed. Engl. 30, 1176-1178 (1991).

7 Voit, B. I. Dendritic polymers: from aesthetic macromolecules to commercially interesting materials. Acta Polym. 46, 87-99 (1995).

8 Voit, B. New developments in hyperbranched polymers. J. Polym. Sci. Part A: Polym Chem. 38, 2505-2525 (2000).

9 Morikawa, A., Kakimoto, M. \& Imai, Y. Synthesis and characterization of new polysiloxane starburst polymers. Macromolecules 24, 3469-3474 (1991). 
10 Tomalia, D. A., Baker, H., Dewald, J., Hall, M., Kallos, G., Martin, R., Ryder, J. \& Smith, P. A new class of polymers: starburst-dendritic macromolecules. Polym. J. 17, 117-132 (1985).

11 Newkome, G. R., Yao, Z., Baker, G. R. \& Gupta, V. K. Cascade molecules: a new approach to micelles. A [27]-arborol. J. Org. Chem. 50, 2003-2004 ( 1985).

12 Morikawa, A., Kakimoto, M. \& Imai, Y. Convergent synthesis of siloxane starburst dendrons and dendrimers via hydrosilylation. Macromolecules 25, 3247-3253 (1992).

13 Morikawa, A., Kakimoto, M. \& Imai, Y. Convergent synthesis of starburst poly(ether ketone) dendrons. Macromolecules 26, 6324-6329 (1993).

14 Yan, D., Gao, C. \& Frey, H. Hyperbranched Polymers. Synthesis, Properties, and Applications (John Wiley \& Sons, Inc., Hoboken, NJ, Canada, 2011).

15 Hawker, C. J., Lee, R. \& Frechet, J. M. J. One-pot synthesis of hyperbranched polyester. J. Am. Chem. Soc. 113, 4583-4588 (1991).

16 Turner, S. R., Viot, B. I. \& Mourey, T. H. All-aromatic hyperbranched polyesters with phenol and acetate and groups: synthesis and characterization. Macromolecules 26, 4617-4623 (1993)

17 Malmstrom, E., Johansson, M. \& Hult, A. Hyperbranched aliphatic polyester. Macromolecules 28, 1698-1703 (1995).

18 Ishida, Y., Jikei, M. \& Kakimoto, M. Synthesis of hyperbranced aromatic polyester by carbon monoxide insertion reaction using palladium catalyst. Poly. Adv. Technol. 11, 684-704 (2000).

19 Bolton, D. H. \& Wooley, K. L. Synthesis and characterization of hyperbranched polycarbonates. Macromolecules 30, 1890-1896 (1997).

20 Bolton, D. H. \& Wooley, K. L. Hyperbranched aryl polycarbonates derived from A(2)B monomers versus $\mathrm{AB}(2)$ monomers. J. Polym. Sci., Part A: Polym. Chem. 40, 823-835 (2002).

21 Yang, G., Jikei, M. \& Kakimoto, M. Successful terminal self-condensation of AB2 monomer to form hyperbranched aromatic polyamide. Macromolecules 31, 5964-5966 (1998).

22 Yang, G., Jikei, M. \& Kakimoto, M. Synthesis and properties of hyperbranched aromatic polyamide. Macromolecules 32, 2215-2220 (1999).

23 Ishida, Y., Sun, A. C. F., Jikei, M. \& Kakimoto, M. Synthesis of hyperbranced aromatic polamides starting from dendrons as ABx monomers: effect of monomer multiplicity on the degree of branching. Macromolecules 33, 2832-2838 (2000).

24 Yamanaka, K., Jikei, M. \& Kakimoto, M. Preparation and properties of hyperbranched aromatic polyimides via polyamic acid methyl ester precursor. Macromolecules 33 , 6937-6944 (2000)

25 Yamanaka, K., Jikei, M. \& Kakimoto, M. Synthesis of hyperbranched aromatic polyimides via polyamic acid methyl ester precursor. Macromolecules 33, 1111-1114 (2000)
26 Yamanaka, K., Jikei, M. \& Kakimoto, M. Preparation of hyperbranched aromatic polyimides without linear units by end capping reaction. Macromolecules 34, 3910-3915 (2001).

27 Takeuchi, M., Jikei, M. \& Kakimoto, M. Preparation of hyperbranched aromatic poly(ether sulfone)s possessing sulfonic acid terminal groups for polymer electrolyte. Chem. Lett. 32, 242-243 (2003).

28 Matsumoto, K. \& Ueda, M. Synthesis of hyperbranched aromatic poly(ether sulfone) with sulfonyl chloride terminal groups. Chem. Lett. 35, 1196-1197 (2006).

29 Miller, T. M., Neenan, T. X., Kwock, E. W. \& Stein, S. M. Dendritic analogs of engineering plastics: a general one-step synthesis of dendritic polyaryl ethers. J. Am. Chem. Soc. 115, 356-357 (1993).

30 Shu, C. F. \& Leu, C. M. Hyperbranched poly(ether ketone) with carboxylic acid terminal groups: synthesis, characterization, and derivatization. Macromolecules 32, 100-105 (1999).

31 Hawker, C. J. \& Chu, F. Hyperbranched poly(ether ketones): manipulation of structure and physical properties. Macromolecules 29, 4370-4380 (1996).

32 Morikawa, A. Preparation and properties of hyperbranched poly(ether ketones) with a various number of phenylene units. Macromolecules 31, 5999-6009 (1998).

33 Shu, C. F., Leu, C. M. \& Huang, F. Y. Synthesis, modification, and characterization of hyperbranched poly(ether ketones). Polymer (Guildf.) 40, 6591-6596 (1999).

34 Kobayashi, H., Komanoya, T., Hara, K. \& Fukuoka, A. Water-tolerant mesoporouscarbon-supported ruthenium catalysts for the hydrolysis of cellulose to glucose. ChemSusChem 3, 440-443 (2010).

35 Kobayashi, H., Yabushita, M., Komanoya, T., Hara, K., Fujita, I. \& Fukuoka, A. Highyielding one-pot synthesis of glucose from cellulose using simple activated carbons and trace hydrochloric acid. ACS Catal. 3, 581-587 (2013).

36 Chung, P.-W., Charmot, A., Olatunji-Ojo, O. A., Durkin, K. A. \& Katz, A. Hydrolysis catalysis of Miscanthus xylan to xylose using weak-acid surface sites. ACS Catal. 4, 302-310 (2014).

37 Evers, R. C., Arnold, F. E. \& Helminiak, T. E. Articulated all-para polymers with 2, 6-benzobisoxazole, 2,6-benzobisthiazole, and 2,6-benzobisimidazole units in the backbone. Macromolecules 20, 925-930 (1981).

38 Hsiao, S. \& Chang, C. Synthesis and properties of aromatic polyamides based on $4,4^{\prime}-[1,4(1,3$ or 1,2)-phenylenedioxy]dibenzoic acid. Macromol. Chem. Phys. 197, 1255-1272 (1996).

39 Eaton, P. E., Carlson, G. R. \& Lee, J. T. Phosphorus pentoxide-methanesulfonic acid. A convenient alternative to polyphosphoric acid. J. Org. Chem. 38, 4071-4073 (1973).

40 Ueda, M. \& Sato, M. Synthesis of aromatic poly(ether ketones). Macromolecules 20, 2675-2678 (1987).

41 Baek, J. \& Tan, L. Synthesis and properties of poly(ether ketone)-block-polybenzobisthiazole-block-poly(ether ketone) ABA triblock copolymers. Macromolecules 41, 1196-1205 (2008). 